ción de las fábulas no es sino un aspecto del conjunto de su crítica; para captar toda su originalidad, conviene situarlo en el complejo marco de la exegesis dieciochesca: sólo así podrá aparecer como un nuevo "desengaño de errores comunes" -y un desengaño nada despreciable. En este, como en tantos otros campos, Feijoo podía reivindicar como adquirido el resultado que, no sin orgullo, proclamaba en el prólogo del cuarto tomo de su Teatro: "Di lo que quisieres, no podrás negarme la novedad de esta obra, la cual me da el carácter de autor original [...]. Tampoco podrás negar que el designio de impugnar errores comunes, sin restricción de materias, no sólo es nuevo, sino grande".

R. Trousson

Université Libre de Bruxelles.

\title{
JOSÉ MARÍA HEREDIA Y JOSÉ DE ESPRONCEDA: ¿UNA CONEXIÓN DIRECTA?
}

Hay en la poesía de José María Heredia una sorprendente semejanza con la de José de Espronceda. Sorprendente, entre otras cosas, porque ningún investigador, que yo sepa, la ha señalado ni mucho menos estudiado, por más que la crítica está de acuerdo en que la vida de los dos poetas tuvo mucho en común, lo cual explicaría, en parte, las semejanzas de su obra. Empecemos por destacar esas analogías extrapoéticas antes de pasar a la poesía misma.

Heredia y Espronceda, contemporáneos (nacido el primero en 1803, el segundo en 1808), experimentaron por igual la influencia de Byron, como dicen las historias literarias, y los dos abrazaron la ideología del liberalismo político de su época; ambos pertenecieron a organizaciones liberales muy activas, Heredia a la de los "Caballeros racionales" y Espronceda a la de los "Numantinos" ; los dos sufrieron destierro a causa de las actividades políticas que desarrollaron en esas organizaciones; los dos, finalmente, escribieron poemas patrióticos de fuerte inspiración liberal (Heredia, "Al sol", "Himno del desterrado"; Espronceda, "Al dos de mayo", "A la patria").

Tales analogias bastan para explicar ciertos hilos comunes en la poesía del cubano y del español, pero no para explicar lo que es a menudo una correspondencia exacta de temas y hasta de palabras, correspondencia que me propongo mostrar comparando el "Niágara" de Heredia con el "Himno al sol" de Espronceda ${ }^{2}$. Como el "Himno al sol"

1 Tanto los "Caballeros racionales" como los "Numantinos", productos del exaltado liberalismo de principios del siglo $\mathrm{xIX}$, lucharon por varios medios contra el gobierno reaccionario de Fernando VII, y sufrieron la consiguiente persecución. Sobre la relación de los dos poetas con las respectivas organizaciones, véanse las siguientes obras: RAFAEL Estenger, Heredia: la incomprensión de si mismo, La Habana, 1938, cap. 3; José María Chacón y Calvo, Estudios heredianos, La Habana, 1939, pp. 102-111; Jorge Campos, Espronceda, Madrid, 1963, p. 30; Vicente Llorens, Liberales y románticos, El Colegio de México, 1954, p. 32.

2 "Niágara", escrito el 15 de junio de $18_{24}$, se publicó en la 1 ạ ed. de las obras de Heredia, hecha en Nueva York en 1825. La 2a ed., impresa en México en 1832, 
se publicó casi diez años después del poema de Heredia, es razonable suponer que Espronceda lo leyó y experimentó su influencia ${ }^{3}$.

En las dos composiciones hay una naturaleza personificada, a la cual el poeta le habla de tú: "Niágara undoso, / tu sublime terror..."; "calma, calla / tu trueno aterrador", dice Heredia; y Espronceda: "Para y óyeme, joh sol!: yo te saludo"; "¡oh sol! a ti llegara...", etc. El poeta confiere atributos humanos a esa naturaleza. Heredia: "déjame contemplar tu faz serena" (cf. también "la aterradora faz" de la catarata); y Espronceda: "vivido lanzas de tu frente el día". Y se trata de una naturaleza cuyo atributo más visible es el poder. El cubano habla del "sublime terror", de la "terrible majestad" del "Niágara poderoso"; y el español dice:

Tranquilo subes del zenit dorado al regio trono en la mitad del cielo, de vivas llamas y esplendor ornado y reprimes tu vuelo [...]

¡Cuánta pompa, grandeza y poderío de imperios populosos [...]!

¿qué fueron ante ti?

Además, la naturaleza sirve de medio para que el poeta eleve su yo al identificarse con ella, identificación posible por el hecho de que se ha creado una naturaleza personificada, humanizada, que comparte con ellos su poder. Esta elevación y afirmación del yo se aprecia claramente en los siguientes versos de Heredia:

\author{
Torrente prodigioso, calma, calla \\ tu trueno aterrador; disipa un tanto \\ las tinieblas que en torno te circundan; \\ déjame contemplar tu faz serena, \\ y de entusiasmo ardiente mi alma llena. \\ Yo digno soy de contemplarte [...].
}

ofrece algunos cambios no muy importantes en el poema que nos interesa. Aquí me sirvo de la ed. de 1825. -Según Joaquín Casalduero, Espronceda, Madrid, 196.1, pp. $137^{-141}$, el "Himno al sol", escrito probablemente entre 1832 y 1833 , fue publicado por primera vez en $E l$ Siglo, el 28 de enero de 1894 . Yo utilizaré la Poesía lírica de Espronceda, ed. N. Alonso Cortés, Zaragoza, 1957.

3 Aunque el libro de Heredia haya sido proscrito en España por el gobierno, Espronceda tuvo amplias oportunidades de leerlo en el extranjero. Según Jorge Campos, op. cit., pp. 9-11, Espronceda, desterrado, estuvo antes de septiembre de 1827 en Portugal, y en septiembre se trasladó a Londres (cf. también VicENTE LloRens, op. cit., p. 32); de allí marchó a Bruselas y París, para volver a Londres en 1832 , y a España en 1833 . Por lo demás, las proscripciones de los gobiernos no siempre son eficaces, y es probable que tenga razón Manuel Pedro González, José Maria Heredia, primogénito del romanticismo hispano, E1 Colegio de México, 1955, para decir de las obras de Heredia (p. 47) que "tanto la primera edición... como la segunda circularon en España antes de que allí se escucharan los primeros ecos románticos". (Dicho sea de paso, el presente artículo, si es que lo que en él digo es convincente, vendría a dar un fundamento concreto, por lo que a Espronceda se refiere, a la tesis de Manuel Pedro González de que Heredia es "el primogénito del romanticismo" en los paises de habla española). 
Con la misma arrogancia afirma Espronceda su yo, exclamando:

Para y óyeme, joh soll: yo te saludo
y extático ante ti me atrevo a hablarte.

Es la misma intimación: que el Niágara guarde silencio, que el sol se detenga en su camino; y el "me atrevo a hablarte" de Espronceda parece casi un eco del "Yo digno soy de contemplarte" de Heredia.

Pero esta concepción romántica de la naturaleza poderosa choca luego con otra, la duda romántica, que mina al fenómeno natural con el que el poeta se ha identificado. Así en el "Niágara":

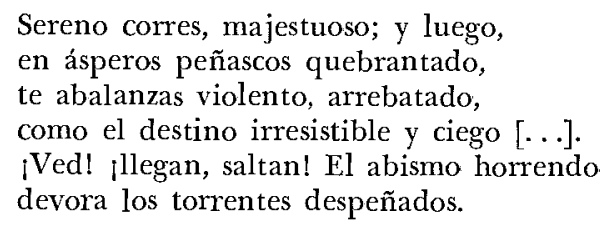

O sea que la potente catarata acaba por ver limitado su poder. Calificado primero de "majestuoso", ahora el Niágara aparece quebrantado y devorado. De manera análoga, Espronceda, que ha declarado su admiración por el sol ("'Cuánto siempre te amé...!", “...extático te vía / y en contemplar tu luz me embebecía"), le dice más tarde:
¿Y habrás de ser eterno, inextinguible? $[\ldots]$
No; que también la muerte,
si de lejos te sigue,
no menos anhelante te persigue.
¿Quién sabe si tal vez pobre destello
eres tú de otro sol que otro universo
mayor que el nuestro un día
con doble resplandor esclarecía!!!

En Espronceda ("¿Quién sabe si tal vez...?”) la duda romántica se declara más explícitamente que en Heredia; pero es claro que sobre la naturaleza de los dos poetas se cierne el mismo anuncio de destrucción.

La duda romántica ha minado el poder de la naturaleza en ambos poetas. Pero ha hecho más, porque ligado a esa naturaleza estaba el yo y su grito de soberbia. Así, en Heredia, la conclusión es ineluctable:

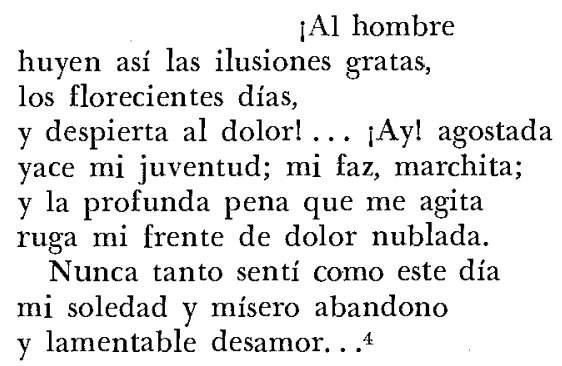

4 Cf. estas líneas de la carta escrita por el poeta dos días después de su visita al Niágara y de la composición del poema: "....corro a satisfacer mi ansiosa curiosidad, muy más encendida con la visión momentánea que había gozado de la mag- 
El grito de arrogancia no se oye más: quedan sólo los acentos de la miseria y el abandono. Y el poeta que ha visto cómo el abismo "devora" al torrente, sabe que "en pocos años / ya devorado habrá la tumba fria" a él mismo, el cantor del Niágara. En cuanto a Espronceda, se dirige melancólicamente al sol con estas palabras:

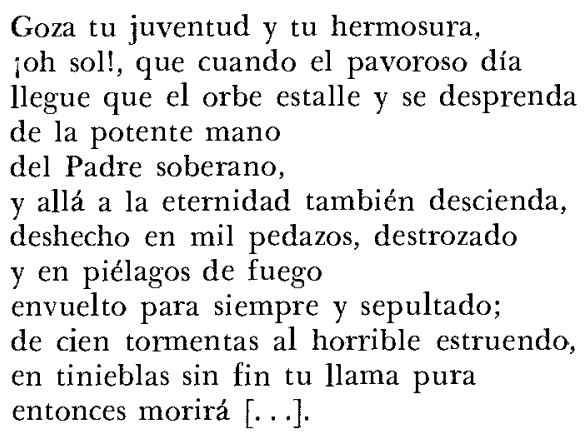

Es la misma falta de esperanza, la misma romántica zozobra en los dos poetas. Con una diferencia: Heredia abandona el plano metafórico y se refiere a sí mismo, a su propia "juventud" agostada, mientras que Espronceda se refiere a la "juventud" del sol, a su hermosura condenada a morir; pero es claro, en vista de su identificación previa con el astro, que lo que nos declara en esos versos es su propia angustiada desesperanza.

Howard Slingerland

Tufts University.

\section{TRES NAHUATLISMOS EN ORIENTE}

En su interesante artículo "Influencia hispanomexicana en el idioma tagalo", $H M x, 14$ (1964-65), 261-271, José Villa Panganiban menciona tres nahuatlismos del tagalo que merecen un examen más detallado.

I. Según ese artículo, el fitónimo mexicano jicama (Pachyrrhizus erosus) ${ }^{1}$ se manifiesta bajo dos formas en las Filipinas: a) singhamas (sust. sing.) y b) hikama. La segunda forma puede considerarse como un préstamo relativamente tardio que el tagalo tomó del español postcolonial. La que nos interesa aquí es la primera: en vista de su estruc-

nífica escena... Yo no sé qué analogia tiene aquel espectáculo solitario y agreste con mis sentimientos... Allí escribí apresuradamente los versos que te incluyo y que sólo expresan débilmente una parte de mis sensaciones. ¡Cuántas cavilaciones sublimes y profundas puede excitar aquella situación en una alma serena y tranquila!" (apud M. García Garófalo, Vida de José Maria Heredia en México, México, 1945, pp. 179-184).

1 La designación Pachyrrhizus erosus se prefiere a la de Pachyrrhizus jicamas. Véase J. I. Briquer, International rules of botanical nomenclature (1935), p. 100. 